\title{
A Study on Green Consumption from the Perspective of Social Comparison
}

\author{
Haiquan Chen, Li Liu, Ruoqing Zhang \\ School of Management, Jinan University, Guangzhou, China \\ Email: liuxt109@gmail.com
}

How to cite this paper: Chen, H.Q., Liu, L. and Zhang, R.Q. (2016) A Study on Green Consumption from the Perspective of Social Comparison. Low Carbon Economy, 7, 137-149.

http://dx.doi.org/10.4236/lce.2016.73013

Received: August 10, 2016

Accepted: September 5, 2016

Published: September 8, 2016

Copyright $\odot 2016$ by authors and Scientific Research Publishing Inc. This work is licensed under the Creative Commons Attribution International License (CC BY 4.0).

http://creativecommons.org/licenses/by/4.0/

(c) (i) Open Access

\begin{abstract}
The study finds that green consumption is the tradeoff that consumers are forced to make between collective interests and personal interests. In reality, consumers think that green consumption is a kind of fashion, and they tend to use herd mentality to choose green consumption, or in order to show their uniqueness that are almost not affected by the influence of the negative features such as high price of green products. This paper explores the relationship between social comparison orientation and green consumption, and examines the mediating effects of in-group identification and the moderating effects of face consciousness, thereby building the conceptual model of this study.
\end{abstract}

\section{Keywords}

Green Consumption, Social Comparison Orientation, Face Consciousness, In-Group Identification

\section{Introduction}

In recent years, with the haze weather, water pollution has a very bad effect, making people miserable. The green consumption is the key to solving the environmental crisis. More enterprises realized the importance and necessity of green consumption. Complying with the demand of green consumption is not only an important means to enhance the competitiveness of enterprises, but also the key to solve the environmental crisis. Green consumption behavior researches become one of the important and lasting concern topics at present.

This paper attempts to solve the following two key issues: one is based on local Chinese face culture, through social identity theory, to explain the relationship between social comparison orientation and green consumption. The other is the social comparison 
as the breakthrough point, through in-group identification and face consciousness to respectively explain the function mechanism and the boundary effect of the social comparison orientation to the green consumption and the model of the mediating effect of the empirical test.

\section{Theoretical Basis and Research Hypothesis}

\subsection{Social Comparison Orientation and Green Consumption}

Green Consumption refers to the environmental consumer behavior that can reduce the resource and environmental pressures. It includes acts (buy recycled products, etc.) in the field of personal and public domain behavior (environmental donation, etc.) [1]. The green consumption behavior is a prosocial behavior [2], it was largely seen as an complex reflecting the interests of the individual and others (Bamberg, Moser, 2007). According to the social exchange theory, social comparison and social rewards (social identity, reputation) have a significant impact on the prosocial behavior [3].

Social comparison can help individuals obtain true and accurate self-awareness, in order to maintain or enhance their image and social status, green consumption can meet the needs of consumers in this area [4]. In different social comparison situation, the impact of social comparison on consumers is different. Social comparison orientation is divided into two dimensions, which is capacity comparison orientation (such as the ability to live with the actual interests), and concept comparison orientation (such as the view of sth.) [5]. Festinger found that the individual's capacity comparison orientation and concept comparison orientation have certain differences [6] [7]. In the context of capacity, Wayment (1995) said that the individual will have a comparison Orientation to be different with others and want to be better than others, which can stimulate prosocial behavior [8]. Different in concept comparison situations, the individual can't completely change their own ability, but he can change their own ideas. When an individual discovers that there is a big difference between him and others, he needs to adjust his own views, reflecting the individual strives to be consistent with others.

Buunk considered closely related to social comparison and environmental behavior [9]. In the face of limited resources of the earth, Van Lange (1999) found that capacity comparison orientation are more to consider their own choice of environmental effects and concern for others on the behavior reaction, will try to take into account the interests of others and social interests and produce higher prosocial behavior, so they are more likely to implement green consumption. Based on this, put forward the hypothesis 1 :

H1: The social comparison orientation has a significant positive effect on green consumption, the capacity comparison orientation were more likely to have green consumption than those concept comparison orientation.

\subsection{In-Group Identification}

In the process of social comparison, scholars began to focus on the role of social identi- 
ty and group identity. Vignoles and Moncaster (2007) also made a social identity is a "seeking common ground" and "divergent" coexistence process, which is looking for individual differences and common belongs groups. Social exchange theory said that in order to obtain social identity or reputation, consumers are willing to sacrifice personal interests and choosing to buy green products for a better society [2] [10] [11].

Morris and Peng (1994) proposed that in-group identification is affected by the reduction of uncertainty and self-enhancement. Reducing uncertainty is the basic need for individuals. Ashforth (2008) found that it reflects individual demand for social order; normative order will make people more determined in the specific social environment to behave, as well as what is expected to do and then find themselves.

Social comparison can help individuals in the absence of objective to obtain true accurate self-understanding and reduce uncertainty, which can improve the individual's in-group identification [2]. On the other hand, self-promotion refers to the positive self-evaluation of the individual through the social identity, which can meet the demand of self-esteem and encourage the individual to have positive in-group identification.

In previous studies, it is considered that the comparison between the inner and outer groups is an important way to produce group identification [12] [13]. Turner and Reynolds (2011) proposed that, in the simplest group paradigm, the individual's cognition will be automatically divided into inner and outer groups. Therefore, even in the lack of outgroup comparison situation, the individual will be unconsciously giving in-group members positively evaluated and more resources in the comparison process, so as to establish and confirm the identity groups. Based on this, put forward the hypothesis 2 :

$\mathrm{H} 2$ : Social comparison orientation has a significant positive effect on in-group identification.

In-group identification is very important for the individual to maintain the interests of the group. Only when an individual identities in-group, he will take "Maximizing the interests of the group" as the decision of conduct and is more willing to participate in the action that fight for the interests of the group. Dawes (2008) believes that the higher the sense of group identification, in the face of the plight of the purchase of green goods, it will strengthen the social constraints and self-control. In the field of green consumption, out of group identification, the individual will follow environmental organization members and purchase similar green products, in order to actively respond to the group members [14].

To sum up, the interaction between social comparison orientation and in-group identification will affect the green consumption behavior of individuals. High social comparison orientation pay more attention to their own to find their own and others of similar and difference, which can reduce the uncertainty and enhance the self-evaluation to be more further prompted the green consumption [12] [15]. Therefore, the in-group identification is the variable of the relationship between social comparison and green consumption. Based on this, this study proposes the hypothesis 3 :

H3: The in-group identification has an intermediary role between social comparison orientation and green consumption. 


\subsection{Face Consciousness}

In addition, $\operatorname{Li}$ (2007) found face will have a "pursuit of individuality" and "herd" double effect. The "face culture" is popular in China, the comparison between people is an essential part and consumers will establish a good social image through social Comparison in the consumption process. In order to enhance their own face, the individual will buy green products to improve prosocial reputation [16].

Francisco (2006) said face consciousness comes from individuals' recognition of their own social image, its consumption of social group effect, as well as the positive function that products stimulate private face. Individuals purchase green products are more for social reasons and less concerned about environmental protection or economic characteristics of the product. This is because people want to be accepted and identified, especially sensitive to the environmental behavior of social and the reputation impact.

Essentially, green consumption is a social problem, "emotional satisfaction" have a significant impact on the study of green consumption. The person with higher face consciousness who is willing to take green products higher premium levels, which will stimulate the choosing to buy environmentally friendly green products. Therefore, face consciousness has become an effective way to promote the individual to carry out the green consumption.

Zheng Yuxiang et al. (2010) found that face consciousness plays an important role in the reference group influence on individual consumer behavior. The level of individual face consciousness is different and the behavior orientation will be different. In the in-group, individuals will make various comparisons (parallel, downlink and uplink), this article speculated that the face awareness will be adjusted the relationship between in-group identification and green consumption through three different mechanisms for comparison:

1) When face consciousness level is higher, there is no difference in the parallel comparison between the individual as the "one", which is consistent with the principle of the social identity theory, and then it has a positive and prosocial behavior. Therefore, this paper argues that the level of the individual in-group identification can be improved by parallel comparison; it will be more concerned about the interests of relevant groups and more conscious consumption of green products, so as to obtain other people's appreciation and then add their own face in respective Groups. 2) "Insiders" get positive self-evaluation by the downlink comparison and individuals will have in-group identification because of "self-interest". In this atmosphere of high face consciousness, in-group identification can satisfy the motivation for self-improvement, in order to enhance their face will purchase more environmentally friendly green products. 3) When the level of face consciousness is low, the individual as "outsider" through the upward comparison with the "insiders" will not produce in-group identification, the motivation of self-promotion is not satisfied and the effect of in-group identification on individual green consumption will be weakened. Therefore, put forward the hypothesis 4 : 
H4: Face consciousness plays a positive moderating effect between in-group identification and green consumption.

$\mathrm{H} 3$ and $\mathrm{H} 4$ together constitute the mediating role of moderation. That is, the in-group identification conducts the influence of social comparison orientation on green consumption, but the mediating effect is moderated by the level of face consciousness. Specifically, when face consciousness level is higher, the effect of in-group identification on individual green consumption is stronger and the positive effect of social comparison on individual green consumption is stronger. Conversely, when face consciousness level is low, the influence of group identity on individual green consumption will be weakened, so the positive effect of social comparison on individual green consumption is weaker. Therefore, put forward the hypothesis 5:

$\mathrm{H} 5$ : The mediating role of in-group identification is through face consciousness positive moderating effect, namely when face consciousness is high, the mediating effect of in-group identification on the relationship between social comparison orientation and green consumption is more significant.

Based on a large amount of literature review and previous studies, this paper constructs a moderated mediation model. The model diagram is shown in Figure 1.

\section{Research Design and Data Analysis}

\subsection{Research Design}

\subsubsection{Questionnaire Design}

This study used questionnaire survey method. All the variables were derived from the domestic and international maturity scale. Survey questionnaires were using Likert 5 scale ( 1 representatives of the total non-consent, 5 on behalf of fully agreed, the higher the score, the more agree). The questionnaire has 3 parts: one is a survey of demographic characteristics (5 questions), namely gender, age, education, income and rank. Two is the measurement of the variables: social comparison orientation (11 topics), which is measured the capability comparison orientation and concept comparison orientation; in-group identification (12 issues); face consciousness (17 questions). Three is the green consumption. We draw on the previous study and design 5 topics to measure.

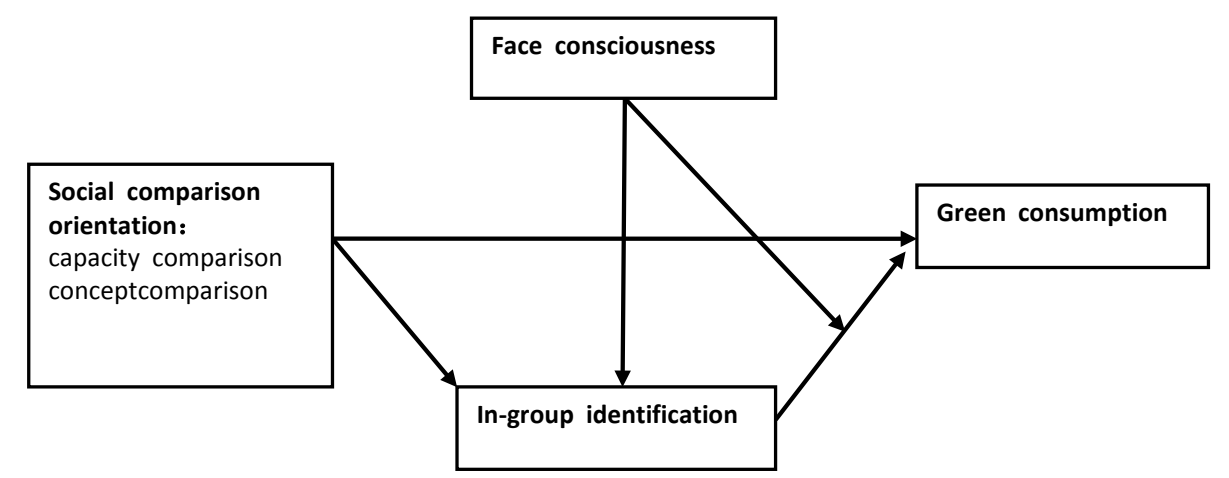

Figure 1. Impact mechanism model of green consumption. 


\subsubsection{Data Collection and Sample Characteristics}

This research used the questionnaire star (a professional data collection platform) to implement the network survey. It lasted 3 months, formal investigation distributed a total of 330 questionnaires, excluding 5 continuous option is the same and manipulate items (which is a power level higher, which pollution is less) significantly answered incorrectly, the final recovery effective questionnaire 287 , efficiency of $87 \%$.

Green products is a new concept, compared to the elderly, young people have the ability to accept new things. Individual with higher education will be more understanding of the environmental responsibility of their own, but also more concerned about the impact of personal behavior on the environment. Different from ordinary products, green products price is high, it needs certain consumption ability. As a result, this research mainly focused on whether the object of investigation is in line with the target consumer group of green products.

The statistics of basic information of the sample are shown in Table 1, sex ratio is basically balanced, including $54.6 \%$ of male and $43.4 \%$ of female. From the age point of view, a total of 199 people in the 18 - 35 years old, accounting for $69.2 \%$, the consumer behavior tends to be more stable, easier to manipulate the impact of external variables on the results. Educational distribution is concentrated in undergraduate and graduate students, accounting for 91.6\%, which helps to better understand the questionnaire materials. From the income level, more than $90 \%$ participants in 5000 Yuan of above. From the ranks, to the management of the majority, accounted for $53.5 \%$ of the total. The above data shows that samples match with green products' target consumer groups (namely young, highly educated and high-income), which is suitable for the study of green consumption. Therefore, the sample has considerable rationality, which lays the foundation for the inference of the reliability of this study.

\subsection{Data Analysis}

\subsubsection{The Reliability and Validity Examination}

This study uses SPSS to test the reliability and validity of the scale. From Table 2, the

Table 1. The basic sample statistics.

\begin{tabular}{cccccc}
\hline Measure & Item & Percentage & Measure & Item & Percentage \\
\hline \multirow{2}{*}{ Gender } & Male & 54.6 & & $18-25$ & 24.5 \\
& Female & 43.4 & Age & $26-35$ & 44.7 \\
& Tertiary and below & 8.4 & & $36-45$ & 26.5 \\
Education & Undergraduate & 46.3 & $>46$ & 5.3 \\
& Graduate and above & 45.3 & & Top & \\
& $<3000$ & 4.8 & & Middle & 6.0 \\
& $3000-5000$ & 5.2 & & Grass-roots management & 29.8 \\
Income & $5001-7000$ & 26.0 & Rank & Technical staff & 29.5 \\
& $7001-9000$ & 31.2 & General staff & $19.0 \%$ \\
\hline
\end{tabular}


Table 2. Correlation coefficient, reliability and AVE value.

\begin{tabular}{cccccc}
\hline & 1 & 2 & 3 & 4 & \\
\hline 1 ACO & 1 & & & & \\
2 CCO & $0.49^{* *}$ & 1 & & \\
3 IGI & $0.53^{* *}$ & $0.44^{* *}$ & 1 & & \\
4 FC & $0.47^{* *}$ & $0.48^{* *}$ & $0.49^{* *}$ & 1 & \\
5 GC & $0.46^{* *}$ & $0.56^{* *}$ & $0.55^{* *}$ & $0.50^{* *}$ & 1 \\
MD & 3.73 & 3.64 & 3.77 & 3.80 & 5.78 \\
SD & 0.65 & 0.89 & 0.78 & 0.72 & 0.76 \\
Cronbach'a & 0.73 & 0.78 & 0.81 & 0.70 & 0.82 \\
CR & 0.71 & 0.73 & 0.75 & 0.72 & 0.73 \\
AVE & 0.56 & 0.62 & 0.64 & 0.53 & 0.52 \\
AVE Square Root & 0.75 & 0.79 & 0.80 & 0.73 & 0.72 \\
\hline
\end{tabular}

Notes: ${ }^{* *}$ Indicates a significant correlation at the 0.01 level (bilateral).

correlation coefficient is between $0.44-0.56$, the correlation of the questionnaire is reasonable, and the quality is reliable. The variables in this study, the Cronbach's $\alpha$ is between the $0.70-0.82, \mathrm{CR}$ is between the $0.71-0.75$, more than 0.70 acceptable limit, indicating that the internal consistency of each measurement scale is good and the overall reliability of the questionnaire is ideal. The absolute value of the correlation coefficient of each variable (between $0.44-0.56$ ) is less than the square root of each variable AVE (between 0.72 - 0.80). Therefore, the scale has good discriminant validity.

\subsubsection{The Main Effect and Moderating Effect}

First, the types of social comparison orientation are divided. The higher the total score, the higher social comparison orientation of the subjects. If the capability comparison orientation score is higher than the concept comparison orientation score, the subjects have stronger capability comparison orientation. According to the previous study habits, the strong capability comparison orientation of individuals called capability, otherwise known as the concept. Specific partition results as shown in Table 3.

Second, comparing mean and conducting one-way ANOVA. The main effect of the test results as shown in Table 4 and Table 5 . There is a significant difference between the green consumption of the capability comparison and the concept comparison $\left(\mathrm{M}_{\mathrm{ca}}\right.$ $=3.73, \mathrm{SD}=1.57$ vs. $\left.\mathrm{M}_{\mathrm{co}}=3.33, \mathrm{SD}=1.89, \mathrm{~F}=6.87, \mathrm{df}=286, p<0.05\right)$. Therefore, the hypothesis 1 has been verified, social comparison has a significant positive effect on green consumption, capability comparison orientation were more likely to carry out green consumption.

Third, hierarchical regression analysis, the regression results as shown in Table 6. The social comparison orientation standardized regression coefficient is significant at the 0.01 level, $\beta$ is $0.61, \Delta \mathrm{R}^{2}$ is statistically significant, therefore, once again support the hypothesis 1 . 
Table 3. Social comparison orientation type.

\begin{tabular}{rcc}
\hline & Capability & Concept \\
\hline Subject & 135 & 152 \\
Percentage & 47.04 & 52.96 \\
\hline
\end{tabular}

Table 4. One-way ANOVA.

\begin{tabular}{ccccc}
\hline & Sum of Squares & Df & Mean Square & F \\
\hline Between Groups & 12.58 & 1 & 12.58 & $6.87^{\star}$ \\
Within Group & 522.89 & 285 & 1.83 & \\
Total & 535.47 & 286 & & \\
\hline
\end{tabular}

Notes: ${ }^{\star} p<0.05,{ }^{* *} p<0.01$.

Table 5. Mean comparison of main effects.

\begin{tabular}{|c|c|c|c|c|c|c|}
\hline & \multirow{2}{*}{$\mathrm{N}$} & \multirow{2}{*}{ Mean } & \multirow{2}{*}{$\begin{array}{c}\text { Std. } \\
\text { Deviation }\end{array}$} & \multirow{2}{*}{$\begin{array}{l}\text { Std. } \\
\text { Error }\end{array}$} & \multicolumn{2}{|c|}{ 95\% Confidence Interval for Mean } \\
\hline & & & & & Lower Bound & Upper Bound \\
\hline Capability & 135 & 3.73 & 1.57 & 0.12 & 3.50 & 3.96 \\
\hline Concept & 152 & 3.33 & 1.89 & 0.13 & 3.08 & 3.58 \\
\hline Total & 287 & 3.52 & 1.74 & 0.09 & 3.33 & 3.67 \\
\hline
\end{tabular}

Table 6. Hierarchical regression results.

\begin{tabular}{|c|c|c|c|c|c|}
\hline \multirow{3}{*}{ Variable } & \multicolumn{5}{|c|}{ Green consumption } \\
\hline & M1 & M2 & M3 & M4 & M5 \\
\hline & $\beta 1$ & $\beta 2$ & $\beta 3$ & $\beta 4$ & $\beta 5$ \\
\hline \multicolumn{6}{|l|}{ First (Control Variable) } \\
\hline Gender & $0.03(0.12)$ & $0.04(0.11)$ & $-0.04(0.08)$ & $0.03(0.14)$ & $0.02(0.11)$ \\
\hline Age & $0.11^{\star}(0.02)$ & $0.14^{\star}(0.03)$ & $0.12^{*}(0.01)$ & $0.11^{\star}(0.01)$ & $0.10^{*}(0.01)$ \\
\hline Education & $0.04(0.05)$ & $0.06(0.04)$ & $0.05(0.03)$ & $0.03(0.06)$ & $0.02(0.05)$ \\
\hline Rank & $0.04(0.07)$ & $-0.02(0.09)$ & $0.03(0.05)$ & $-0.05(0.06)$ & $-0.05(0.07)$ \\
\hline Income & $0.05(0.05)$ & $-0.03(0.06)$ & $0.04(0.07)$ & $0.02(0.05)$ & $-0.03(0.08)$ \\
\hline \multicolumn{6}{|l|}{ Second (Main Effect) } \\
\hline $\begin{array}{c}\text { Social comparison } \\
\text { orientation }\end{array}$ & & $0.61^{\star}(0.04)$ & $0.59^{*}(0.03)$ & & \\
\hline Face consciousness & & & $0.19^{*}(0.03)$ & $0.14^{\star}(0.03)$ & $0.16^{\star}(0.03)$ \\
\hline In-group identification & & & & $0.46^{*}(0.03)$ & $0.48^{\star}(0.04)$ \\
\hline \multicolumn{6}{|l|}{ Third (Moderated Effect) } \\
\hline In-group ${ }^{\star}$ Face & & & & & $0.09^{\star}(0.04)$ \\
\hline $\mathrm{F}$ & 7.05 & $8.69^{\star *}$ & $106.22^{\star *}$ & $32.08^{\star *}$ & $28.56^{* *}$ \\
\hline $\mathrm{R}^{2}$ & 0.03 & 0.04 & 0.51 & 0.23 & 0.24 \\
\hline Adjusted $\mathrm{R}^{2}$ & 0.03 & 0.03 & 0.51 & 0.23 & 0.23 \\
\hline$\Delta \mathrm{R}^{2}$ & 0.01 & $0.01^{\star *}$ & $0.49^{* *}$ & $0.20^{* *}$ & $0.01^{* *}$ \\
\hline
\end{tabular}

Notes: Table value is the standard regression coefficient, the bracket is standard error; $\mathrm{N}=287 ;{ }^{*} p<0.05,{ }^{*} p<0.01$. 
At the same time, it can be known from the model M7 in Table 7, the influence of social comparison orientation on in-group identification is significant $(\beta=0.24, p<$ $0.01),(\mathrm{F}=8.79, p<0.01), \Delta \mathrm{R}^{2}$ is statistically significant, therefore verify the hypothesis 2 , the social comparison orientation has a significant positive effect on the in-group identification. In addition, the model 6 through table M1 shows that age(Control variables) has positive impact on green consumption $(\beta=0.11, p<0.01)$, also explained $3 \%$ of the variance of green consumption, while the remaining four control variables on green consumption is not significant.

At last, from the model M5 of Table 6, it is known that the interaction effect between in-group identification and face consciousness has a significant positive effect on green consumption $(\beta=0.09, p<0.05)$. This shows that the higher the level of face consciousness of individual perception, the greater impact of in-group identification on green consumption, hypothesis 4 was further verified. The moderating role of face consciousness between group identity and green consumption is established. Figure 2 shows the trend of this interaction.

Table 7. The mediating effect of in-group identification.

\begin{tabular}{|c|c|c|c|c|c|}
\hline \multirow{2}{*}{ Variable } & M6 & M7 & M8 & M9 & M10 \\
\hline & In-group & In-group & In-group & Green & Green \\
\hline \multicolumn{6}{|l|}{ First (Control Variable) } \\
\hline Gender & $0.03(0.12)$ & $0.03(0.11)$ & $-0.04(0.10)$ & $0.02(0.12)$ & $0.03(0.14)$ \\
\hline Age & $0.02(0.01)$ & $0.02(0.02)$ & $0.01^{\star}(0.01)$ & $0.11^{\star}(0.01)$ & $0.10^{*}(0.01)$ \\
\hline Education & $0.06(0.06)$ & $0.07(0.05)$ & $0.07(0.07)$ & $0.01(0.05)$ & $0.01^{*}(0.05)$ \\
\hline Rank & $0.08(0.09)$ & $0.09(0.09)$ & $0.08^{\star}(0.07)$ & $-0.06(0.05)$ & $-0.05(0.06)$ \\
\hline Income & $-0.03(0.06)$ & $-0.02(0.05)$ & $-0.02(0.07)$ & $-0.0020 .05)$ & $-0.00(0.07)$ \\
\hline \multicolumn{6}{|l|}{$\begin{array}{c}\text { Second } \\
\text { (Independent Variable) }\end{array}$} \\
\hline $\begin{array}{c}\text { Social comparison } \\
\text { orientation }\end{array}$ & & $0.24^{*}(0.04)$ & $0.12^{\star}(0.03)$ & $0.17^{\star}(0.03)$ & $0.17^{\star}(0.03)$ \\
\hline Face consciousness & & & $0.22^{\star}(0.03)$ & $-0.08(0.03)$ & $-0.07(0.03)$ \\
\hline \multicolumn{6}{|l|}{ Third (Mediated Variable) } \\
\hline In-group identification & & & & $0.46^{\star}(0.04)$ & $0.47^{\star \star}(0.03)$ \\
\hline \multicolumn{6}{|l|}{$\begin{array}{c}\text { Fourth } \\
\text { (Interactive variables) }\end{array}$} \\
\hline In-group ${ }^{\star}$ Face & & & & & $0.08^{\star}(0.03)$ \\
\hline $\mathrm{F}$ & 6.14 & $8.79^{\star *}$ & $6.92^{\star *}$ & $21.87^{\star *}$ & $27.97^{\star *}$ \\
\hline $\mathrm{R}^{2}$ & 0.03 & 0.05 & 0.06 & 0.20 & 0.26 \\
\hline Adjusted $\mathrm{R}^{2}$ & 0.03 & 0.05 & 0.05 & 0.19 & 0.25 \\
\hline$\Delta \mathrm{R}^{2}$ & 0.02 & $0.04^{* *}$ & $0.01^{\star *}$ & $0.14^{* *}$ & $0.07^{\star *}$ \\
\hline
\end{tabular}

Notes: the value in the table is the standard regression coefficient, and the bracket is the standard error; $\mathrm{N}=287 ;{ }^{*} p$ $<0.05,{ }^{* *} p<0.01$. 


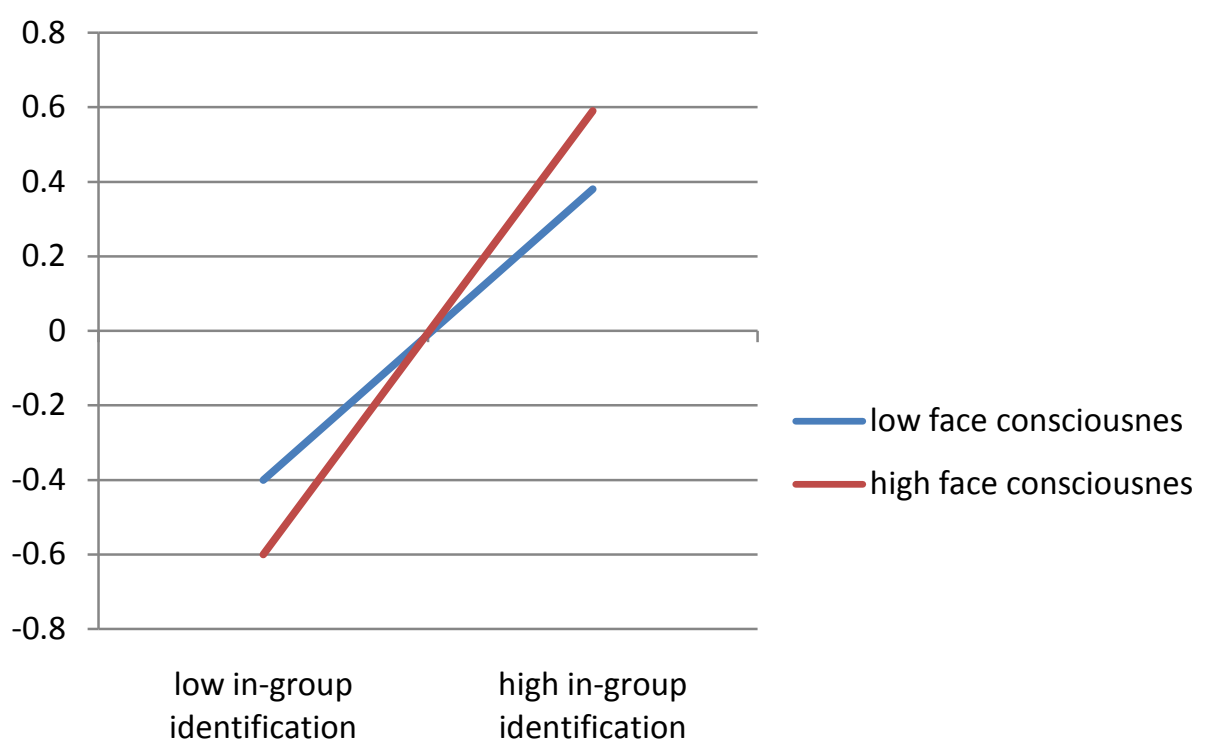

Figure 2. The interaction of in-group identification and face consciousness.

\subsubsection{The Mediating Effect and Moderated Mediator}

The mediating effect of in-group identification is adjusted by face consciousness; therefore, the in-group identification is the moderated mediator. In this study, four step Wen Zhonglin, etc. (2006) provided to test the mediating effect of moderation:

One is the green consumption regression analysis on social comparison orientation and face consciousness. The results from the model M3 in Table 6 can be seen, social comparison orientation $(\beta=0.59, p<0.01)$ and face awareness $(\beta=0.19, p<0.01)$ have a significant impact on green consumption, which meets the requirements of the first step.

Two is the social comparison orientation and face consciousness to carry the regression analysis on in-group identification. The results from the model M8 in Table 7 can be seen, social comparison orientation $(\beta=0.12, p<0.01)$ and face awareness $(\beta=0.22$, $p<0.01$ ) have a significant impact on in-group identification, which meets the requirements of the second step.

Three is the regression model of the table M97 will be included in the model of in-group identification, the social comparison orientation's explanation effect on green consumption decreased $(\beta=0.17, p<0.01)$, but it is still significant and the mediating effect of in-group identification is significant $(\beta=0.46, p<0.01)$. This meets the requirements of the third step, the relationship between the social comparison orientation and green consumption is partially mediated by in-group identification. Hypothesis 3 is supported by the data.

Four is the regression model of table M10 7, the coefficient of interaction effect (in-group identification ${ }^{*}$ face consciousness) is significant $(\beta=0.08, p<0.05)$. Thus, when face consciousness is higher, the mediating role of in-group identification in social comparison and green consumption will be more significant, it is verified that the hypothesis 5 , the mediating role of in-group identification is the positive moderated by face consciousness. 


\section{Conclusion and Future Research}

\subsection{Conclusions and Management Implications}

This study reveals the mediating mechanism and boundary effect of social comparison on green consumption, and empirically verifies the mediating role model. The empirical results from the third chapter can be seen that all the assumptions of this paper are supported and the results of the study will be discussed separately:

1) The social comparison orientation has a significant positive effect on green consumption. The consumer behavior has become a social identification and mean, that is the process of shaping and maintaining the identification of the individual. Therefore, enterprises should first analyze the characteristics of the target consumer groups (the existing needs, values and lifestyle, etc.) to play its reference group influence and then make green products.

2) Social Comparison orientation is partially mediated by in-group identification within the positive impact of green consumption, to emphasize the inherent relationship between green products and identity among group members (Jaworski, MacInnis, 1986). However, if the business is expected to lead the customer to the group as a reference group, you must first confirm the customer identification group. Based on this, a sense of intimacy of the product (or brand) should be enhanced so that customers have more sense of belonging to the group. In this way, customers will be due to the relevant product (or brand) recognition to promote green product consumption and even lead the green consumption trend.

3) The relationship between in-group identification and green consumption is significantly moderated by face consciousness. Enterprises with celebrity strategy, environment-friendly strategies to reconstruction of the product or brand image, will closely link the image of the fashion trends, social identity, to achieve the purpose of "seeking common ground" or "divergent".

\subsection{Innovations}

Green consumer willingness and green consumption phenomenon is easy to study only from the behavior representation, the existing research rarely in-depth study from the aspects of mechanism of consumer psychology social comparison. This study provides a new perspective for the study of green consumption, which is helpful to analyze the internal mechanism and boundary conditions of green consumption. It can be regarded as a useful attempt to make up for the lack of the integration model of green consumption and lack of green consumption psychological mechanism in the past.

From the existing research results about consumer social comparison, research in this area is scattered and not comprehensive. It is difficult to find the results of the research on the impact of social comparison on the behavior of a particular consumer behavior. In this paper, based on the consumer social comparison orientation differences, an empirical study on the formation of consumers' green consumption, the research field of social comparison extends from the field of psychology to the field of marketing, and itself is a kind of development and innovation. 


\subsection{Limitations and Future Research}

\subsubsection{Limitations}

Due to the limitations of the level, time and financial resources, this study has the following deficiencies:

On the one hand, this article only discusses the purchase behavior of green consumption, ignoring the use of behavior and disposal of the impact mechanism. Secondly, in order to stimulate Subjects' face consciousness, this paper uses energy-saving vehicles as green products to explore, ignoring the other in the non-public consumption of green products. All of the above to a certain extent, once again reduced the conclusion of the universal.

On the other hand, as a kind of complicated and changeable social personality characteristic, the research of social comparison has only adopted a questionnaire survey. Although it can effectively measure the psychological state of being tested, it can't fully reflect the opinions and attitudes of the subjects. Therefore, it is inevitable to have measurement errors and can't fully investigate the object of study.

\subsubsection{Future Research}

On the one hand, the future research on green consumption can increase the use of green consumption behavior and disposal behavior of these two dimensions, and further enrich the formation mechanism of green consumption. In addition, to segments the type of green products.

On the other hand, according to the measurement of social comparison orientation, we can adopt the method of horizontal and vertical design of the future. In particular, the subjects were followed by a long period of follow-up survey, interviews and combined with experimental methods. Therefore, in the future, we can on the basis, through the extension of social comparison theory connotation, more fully reveal the dynamic relationship between them.

\section{References}

[1] Kazdin, A.E. (2009) Psychological Science's Contributions to a Sustainable Environment: Extending Our Reach to a Grand Challenge of Society. American Psychologist, 64, 339-356. http://dx.doi.org/10.1037/a0015685

[2] Griskevicius, V., Tybur, J.M. and van den Bergh, B. (2010) Going Green to Be Seen: Status, Reputation, and Conspicuous Conservation. Journal of Personality and Social Psychology, 98, 392-404. http://dx.doi.org/10.1037/a0017346

[3] Blau, P.M. (1964) Justice in Social Exchange. Sociological Inquiry, 34, 193-206. http://dx.doi.org/10.1111/j.1475-682X.1964.tb00583.x

[4] Klein, W.M.P. (2003) Effects of Objective Feedback and "Single Other" or "Average Other" Social Comparison Feedback on Performance Judgments and Helping Behavior. Personality and Social Psychology Bulletin, 29, 418-429. http://dx.doi.org/10.1177/0146167203251195

[5] Buunk, A.P. and Gibbons, F.X. (2007) Social Comparison: The End of a Theory and the Emergence of a Field. Organizational Behavior and Human Decision Processes, 102, 32-42.

[6] Festinger, L.A. (1954) Theory of Social Comparison Processes. Human Relations, 7, 127- 
140. http://dx.doi.org/10.1177/001872675400700202

[7] Festinger, L. (1957) A Theory of Social Comparison Processes. Human Relations, 5, 66-71.

[8] Weinstein, N. and Ryan, R.M. (2010) When Helping Helps: Autonomous Motivation for Prosocial Behavior and Its Influence on Well-Being for the Helper and Recipient. Journal of Personality and Social Psychology, 98, 222-244. http://dx.doi.org/10.1037/a0016984

[9] Buunk, B.P., Wilmar, B. and Burnout, S. (2005) A Perspective from Social Comparison Theory. Journal of Experimental Social Psychology, 14, 201-209.

[10] Semmann, D., Krambeck, H. and Milinski, M. (2005) Reputation Is Valuable within and outside One's Own Social Group. Behavioral Ecology and Sociohiology, 57, 611-618. http://dx.doi.org/10.1007/s00265-004-0885-3

[11] Amotz, Z. (1995) Altruism as a Handicap: The Limitations of Kin Selection and Reciprocity. Journal of Avian Biology, 26, 1-3. http://dx.doi.org/10.2307/3677205

[12] Tajfel, H. and Turner, J.C. (1979) Social Comparison and Group Interest in In-Group Favoritism. European Journal of Social Psychology, 9, 187-204. http://dx.doi.org/10.1002/ejsp.2420090207

[13] Tajfel, H. and Turner, J.C. (1986) The Social Identity Theory of Intergroup Behavior. Psychology of Intergroup Relations, 5, 7-24.

[14] De Cremer, D. and Van Dijk, E. (2002) Reactions to Group Success and Failure as a Function of Identification Level; A Test of the Goal-Transformation Hypothesis in Social Dilemmas. Journal of Experimental Social Psychology, 38, 435-442. http://dx.doi.org/10.1016/S0022-1031(02)00009-4

[15] Gibbons, F.X. and Buunk, B.P. (1999) Individual Differences in Social Comparison: Development of a Scale of Social Comparison Orientation. Journal of Personality and Social Psychology, 76, 129-142. http://dx.doi.org/10.1037/0022-3514.76.1.129

[16] Van Vugt, M. (2001) Community Identification Moderating the Impact of Financial Incentives in a Natural Social Dilemma: Water Conservation. Personality and Social Psychology Bulletin, 27, 1440-1449. http://dx.doi.org/10.1177/01461672012711005 
Submit or recommend next manuscript to SCIRP and we will provide best service for you:

Accepting pre-submission inquiries through Email, Facebook, LinkedIn, Twitter, etc. A wide selection of journals (inclusive of 9 subjects, more than 200 journals)

Providing 24-hour high-quality service

User-friendly online submission system

Fair and swift peer-review system

Efficient typesetting and proofreading procedure

Display of the result of downloads and visits, as well as the number of cited articles

Maximum dissemination of your research work

Submit your manuscript at: http://papersubmission.scirp.org/ 